\title{
Genetic characterisation of resistance to metal ions in methicillin-resistant Staphylococcus aureus: elimination of resistance to cadmium, mercury and tetracycline with loss of methicillin resistance
}

\author{
S. M. POSTON and F-L LI SAW HEE
}

Department of Microbiology, United Medical and Dental Schools of Guy's and St Thomas's Hospitals, Guy's Medical School, London SE1 9RT

\begin{abstract}
Summary. Susceptibility to six metal ions-cadmium $(\mathrm{Cd})$, mercury $(\mathrm{Hg})$, arsenate (Asa), arsenite (Asi), antimony ( $\mathrm{Sb})$ and zinc ( $\mathrm{Zn}$ - - was tested in 23 independent isolates of methicillin-resistant Staphylococcus aureus (MRSA) obtained from Guy's Hospital (GH) during 1984-1986, which included 10 isolates of the UK epidemic EMRSA-1 strain. Strains were also tested for resistance to antibiotics and the nucleic-acid-binding compounds propamidine isethionate and ethidium bromide. A further 19 methicillin-resistant isolates, including 10 EMRSA-1 were obtained from other sources. Ten methicillin-sensitive, antibiotic sensitive isolates were from Guy's Hospital. Resistance to $\mathrm{Hg}$ was associated with methicillin resistance in 19 of the 20 EMRSA-1 isolates, all of which were resistant to Cd. Resistance to $\mathrm{Cd}$ and $\mathrm{Hg}$ was found in 13 out of 22 other MRSA isolates. $\mathrm{Hg}$ resistance was not present in the methicillin-sensitive isolates which were often (13 out of 19) moderately resistant to $\mathrm{Cd}$. Multiple resistance to metal ions, including resistance to $\mathrm{Hg}$, Asa, Asi and $\mathrm{Sb}$, was uncommon. Resistance to $\mathrm{Cd}(\mathrm{MIC}>32 \mathrm{mg} / \mathrm{L}$ or $8-16 \mathrm{mg} / \mathrm{L}$ ) was associated with increased resistance to $\mathrm{Zn}$. In 11 of the consecutive MRSA isolates from Guy's Hospital seven distinct strains were recognised by phage type. Methicillin resistance in these strains varied from 16 to $1024 \mathrm{mg} / \mathrm{L}$ at $30^{\circ} \mathrm{C}$ with a 2-8-fold lower minimum inhibitory concentration at $37^{\circ} \mathrm{C}$ indicating some degree of heterogeneity. Representatives of the EMRSA-1 strain had the higher levels of resistance. Loss of methicillin resistance occurred in $0 \cdot 2-5 \cdot 0 \%$ of colonies tested after storage at room temperature in 10 of these isolates. In some EMRSA-1 strains this loss was associated with loss of $\mathrm{Cd}, \mathrm{Zn}$ and, usually, $\mathrm{Hg}$ resistance, and a 4-fold reduction in resistance to tetracycline. These resistance determinants were not transferred by transduction of plasmids from these strains and plasmid-free strains retained these markers, indicating that a chromosomal region is involved. These findings support evidence for a close relationship between the EMRSA-1 strain in the UK and the recent epidemic MRSA strain in eastern Australia. In the strains which lost methicillin resistance independently of other markers, $\mathrm{Cd}$ resistance and $\beta$-lactamase production were plasmid encoded, as shown by co-elimination and co-transduction of these markers. In addition to $\mathrm{Cd}$ and penicillin resistance, the markers encoded by these plasmids included resistance to Asa, Asi and $\mathrm{Sb}$ in two strains, resistance to $\mathrm{Hg}$, propamidine isethionate and ethidium bromide in a further two isolates, and for resistance to $\mathrm{Hg}$, Asa, Asi and $\mathrm{Sb}$, kanamycin, neomycin and streptomycin, and erythromycin and clindamycin in one strain. Methicillin resistance was transduced from strain GH34 to strain 80CR5 with phage 80. MICs of methicillin $(1024 \mathrm{mg} / \mathrm{L})$ were higher for transductants than the donor strain $(32-64 \mathrm{mg} / \mathrm{L})$ at $30^{\circ} \mathrm{C}$ and showed little heterogeneity when tested at $37^{\circ} \mathrm{C}$.
\end{abstract}

\section{Introduction}

Methicillin-resistant Staphylococcus aureus(MRSA) strains were reported in the UK by Jevons as early as $1961 .^{1}$ The expression of resistance is often heterogeneous, with only a minority of cells ( 1 in $\left.10^{3}-10^{6}\right)$ showing resistance to higher levels of methicillin. ${ }^{2}$ In heterogeneous strains, expression of resistance is greater at $30^{\circ} \mathrm{C}$ than at $37^{\circ} \mathrm{C}$. Resistance is also affected by other growth conditions. ${ }^{3}$ Since 1970 , strains responsible for outbreaks of infection have become dominant in several countries. Epidemic strains from eastern Australia and London are similar in characteristics, including the carriage of a large plasmid (c. $30 \mathrm{~kb}$ ) coding for resistance to the nucleicacid-binding (NAB) compounds propamidine ise-

Received 17 May 1990; accepted 15 Aug. 1990. 
thionate $(\mathrm{Pi})$ and ethidium bromide $(\mathrm{Eb})$, to gentamicin, tobramycin and kanamycin and sometimes to penicillin ( $\beta$-lactamase production) and trimethoprim. ${ }^{4,5}$ Plasmids coding for resistance to $\mathrm{Pi}, \mathrm{Eb}$, cadmium $(\mathrm{Cd})$, mercury $(\mathrm{Hg})$ and penicillin, occur in epidemic MRSA in south-east Asia ${ }^{6}$ are found in Dublin $^{7}$ and, occasionally, in the UK. ${ }^{4,8}$ The large $(c .30 \mathrm{~kb}) \beta$-lactamase plasmids in hospital isolates of $S$. aureus isolated before 1970 carried different resistance determinants, of ten coding for multiple resistance to metal ions including $\mathrm{Cd}, \mathrm{Hg}$ and arsenate (Asa). ${ }^{9-12}$ $\mathrm{Hg}$ resistance was considered to be a useful marker for hospital strains. ${ }^{13}$ Many of these plasmids were related and belonged to the same incompatibility group (Inc I). Townsend et al. ${ }^{14}$ showed that a NAB plasmid from recent MRSA isolates in Australia also belonged to Inc I, which could have displaced the $\beta$ lactamase, metal-ion-resistance plasmid of the same incompatibility group. The genetic basis of a number of these plasmid types has been reviewed recently. ${ }^{15}$

In a recent study of hospital isolates of $S$. aureus in the $\mathrm{UK}$, resistance to $\mathrm{Hg}$ was common only in methicillin-resistant isolates. ${ }^{16}$ In a large scale survey of $S$. aureus isolates in Denmark between 1967 and $1974,{ }^{17}$ a decrease in the incidence of resistance to $\mathrm{Hg}$ was shown. Isolates of MRSA are frequently antibiotic multi-resistant and chromosomal resistance to erythromycin is common. ${ }^{18,19} \mathrm{Cd}$ and $\mathrm{Hg}$ resistance is also chromosomally mediated in recent isolates of MRSA. $^{20}$ An epidemic strain predominating in London and the south-east of England has a characteristic phage type and antibiotic-susceptibility pattern and has been designated EMRSA-1 ${ }^{19,21}$ Loss of methicillin resistance is readily detected after storage at room temperature. ${ }^{22}$ Simultaneous loss of $\mathrm{Cd}$ and $\mathrm{Hg}$ resistance may occur with loss of methicillin resistance in S. epidermidis. ${ }^{23}$ In S. aureus, Matthews et al. $^{24}$ showed that a large deletion of $30-40 \mathrm{~kb}$, in an epidemic strain from eastern Australia, contained sequences in a 24-27-kb fragment responsible for resistance to methicillin, $\mathrm{Hg}$ and $\mathrm{Cd}$ and for resistance to tetracycline. ${ }^{24,25}$ Additional chromosomally determined resistance to tetracycline and to minocycline also occurs in Australian MRSA isolates ${ }^{26}$ and in EMRSA-1 isolates in the UK. ${ }^{19}$

Methicillin resistance is often difficult to transduce in $S$. aureus. The recovery of transductants has been shown to depend on the presence of phage and plasmid carriage $^{27}$ or on $\beta$-lactamase production in the recipient. ${ }^{28}$ In $S$ epidermidis, the presence of the chromosomal determinants for $\mathrm{Cd}$ and $\mathrm{Hg}$ resistance appears to play a role in determining recipient effectiveness for transduction of methicillin resistance. ${ }^{23}$

The present study was undertaken to assess the incidence of resistance to metal ions in MRSA isolated at a London hospital between 1984 and 1986. The genetic location of the determinants was established by transduction and elimination of markers in selected isolates. The co-elimination of chromosomal markers with loss of methicillin resistance was also established.

\section{Materials and methods}

\section{Bacterial strains, media and phages}

Twenty-three isolates were consecutive but independent MRSA isolates from Guy's Hospital (GH isolates) obtained during 1984-1986; these included 10 isolates of the UK epidemic strain EMRSA-1. In outbreaks of infection only one isolate was included. The resistance phenotypes and phage types of 11 isolates studied for loss of methicillin resistance are shown in table I. Ten methicillin-sensitive $S$. aureus isolates obtained from Guy's patients in 1986 were also examined. Isolates provided by $\mathrm{Dr} \mathbf{R}$. $\mathrm{R}$. Marples (Central Public Health Laboratory, Colindale Avenue, London) from various UK sources, included 10 EMRSA-1, nine other MRSA (OMRSA) and 10 methicillin-sensitive but antibiotic-resistant isolates (ORSA). ${ }^{19}$ Heterogeneous methicillin-resistant S. aureus strains CRF612 and 10442 were provided by Dr J. Richardson (CPHL). Recipients in transduction experiments were a rifampicin-resistant mutant of the restriction-deficient strain $80 \mathrm{CR} 5,{ }^{29}$ a rifampicinresistant mutant of strain SA113, ${ }^{30}$ SA113R, provided by $\mathrm{Dr} \mathrm{J}$. Naidoo, or strain 8325-4 (RN 450), which is phage- and plasmid-free, provided by $\operatorname{Dr} R$. Novick. The plasmid-free strain NCTC $8325(8325 \mathrm{~N})$ was provided as a rifampicin-resistant mutant $8325 \mathrm{NR}$ by Dr J. Naidoo.

Bacteria were stored at $-70^{\circ} \mathrm{C}$ in Nutrient Broth No. 2 (NB; Oxoid) containing glycerol $10 \% \mathrm{v} / \mathrm{v}$. Cultures were maintained on Blood Agar (Tissue

Table I. Antimicrobial resistance and phage type of 11 consecutive MRSA isolates from Guy's Hospital

\begin{tabular}{|c|c|c|}
\hline $\begin{array}{l}\text { Isolate } \\
\text { no. }\end{array}$ & $\begin{array}{l}\text { Phage type } \\
\text { (100RTD) }\end{array}$ & Resistance phenotype* \\
\hline GH13† & $85 w$ & $\begin{array}{l}\text { Mc Pc Pi Eb Gm Km Tm Tc Sm Em Tp } \\
\text { Cd Hg }\end{array}$ \\
\hline GH25† & $85 w$ & $\begin{array}{l}\text { Mc Pc Gm Km Tm Tc Cm Sm Em Tp } \\
\text { Cd Hg }\end{array}$ \\
\hline GH28† & $85 w$ & $\begin{array}{l}\text { Mc Pc Pi Eb Gm Km Tm Tc Cm Sm } \\
\text { Em Tp Cd Hg }\end{array}$ \\
\hline GH31† & $85 w$ & $\begin{array}{l}\text { Mc Pc Pi Eb Gm Km Tm Tc Cm Sm } \\
\text { Em Tp Cd Hg }\end{array}$ \\
\hline GH19 & NT or $29 w / 85$ & $\begin{array}{l}\text { Mc Pc Pi Eb Gm Km Tm Tc Sm Nm } \\
\text { Em Tp Cd Hg }\end{array}$ \\
\hline GH30 & NT or $29 w / 85$ & $\begin{array}{l}\text { Mc Pc Pi Eb Gm Km Tm Tc Sm Nm } \\
\text { Em Tp Cd Hg }\end{array}$ \\
\hline GH27 & 85 (RTD) & $\begin{array}{l}\text { Mc Pc Gm Km Tm Tc Sm Em Tp Cd } \\
\text { Asa Asi Sb }\end{array}$ \\
\hline GH32 & NT & $\begin{array}{l}\text { Mc Pc Gm Km Tm Tc Sm Em Fa Rf } \\
\text { Cd Hg }\end{array}$ \\
\hline GH23 & $\begin{array}{l}52 / 52 \mathrm{~A} / 80 / \\
95 / 75 / 83 \mathrm{~A}\end{array}$ & Mc Pc Tc Sm Km Nm Em Fa Cd ${ }^{M}$ \\
\hline GH24 & $\begin{array}{l}6 / 47 / 54 / 75 / \\
77 / 84 / 85 / 81 \\
\text { (RTD) }\end{array}$ & $\begin{array}{l}\text { Mc Pc Gm Km Tm Tc Em Tp Rf Cd } \\
\text { Asa Asi Sb }\end{array}$ \\
\hline GH34 & 80 (RTD) & $\begin{array}{l}\text { Mc Pc Gm Km Tm Tc }{ }^{\mathrm{L}} \mathrm{Cm} \text { Sm Nm Em } \\
\text { Cd Hg Asa Asi Sb }\end{array}$ \\
\hline
\end{tabular}

${ }^{\mathrm{L}}$, low level resistance (MIC $4 \mathrm{mg} / \mathrm{L}$ ); ${ }^{\mathrm{M}}$, moderate resistance (MIC

$8-16 \mathrm{mg} / \mathrm{L}$ ).

* See Materials and methods.

† EMRSA-1. 
Culture Services) or Tryptic Soy Agar (TSA) prepared from Tryptic Soy Broth (TSB; Difco) solidified with Bacteriological Agar No. 1 (Oxoid) 1\% w/v. Nutrient Agar (NA) was prepared from NB solidified with agar $1 \%$.

Phages used for propagation on donor strains in transduction experiments were phage 80 , phage $80 \alpha$ (provided by Dr R. Novick), phage 83A (provided by Dr B. Berger-Bächi) and phage 24 obtained by UV induction of strain GH24. Phages were obtained by UV induction from strains GH19, GH30, GH32 and GH27 for testing as donors.

\section{Susceptibility tests}

Antibiotic disk sensitivity tests and tests for susceptibility to the NAB compounds Pi (provided by RhonePoulenc Ltd) and Eb (Sigma), were performed on Diagnostic Sensitivity Test Agar with lysed blood (Tissue Culture Services, Difco), with a semi-confluent inoculum prepared in phosphate-buffered saline. Antibiotic disks (Oxoid) were penicillin (Pc, 1.5 units) and (drug content in $\mu \mathrm{g}$ ), methicillin (Mc, 10), tetracycline (Tc, 10), chloramphenicol $(\mathrm{Cm}, 10)$, streptomycin $(\mathrm{Sm}, 10)$, neomycin $(\mathrm{Nm}, 10)$, kanamycin $(\mathrm{Km}, 5)$, gentamicin $(\mathrm{Gm}, 10)$, tobramycin $(\mathrm{Tm}$, $10)$, erythromycin $(\mathrm{Em}, 5)$, clindamycin $(\mathrm{Cl}, 2)$, spectinomycin ( $\mathrm{Sp}, 100)$, trimethroprim $(\mathrm{Tp}, 2.5)$, fusidic acid $(\mathrm{Fa}, 5$ or 10$)$, rifampicin ( $\mathrm{Rf}, 2)$, vancomycin (Va, 30) and novobiocin (No, 5).

Disks containing Eb $50 \mu \mathrm{g}$ and $\mathrm{Pi} 50 \mu \mathrm{g}$ were tested by Stokes's method with $S$. aureus NCTC 6571 as the sensitive control. Sensitivity tests for metal ions were by Stokes's method on $0.3 \mathrm{CY}$ agar without added calcium ${ }^{31}$ employing strain $8325 \mathrm{NR}$ as the sensitive control because strain NCTC 6571 is resistant to Cd, Asa and Asi. Disks for metal-ion sensitivities were impregnated with $3 \mathrm{CdSO}_{4} .8 \mathrm{H}_{2} \mathrm{O}(\mathrm{Cd}) 20 \mu \mathrm{g}$, phenyl mercuric nitrate $(\mathrm{Hg}) 0.13 \mu \mathrm{g}$, inorganic mercury $\mathrm{Hg}\left(\mathrm{NO}_{3}\right)_{2} . \mathrm{H}_{2} \mathrm{O} 6.7 \mu \mathrm{g}$ or $10 \mu \mathrm{g}, \mathrm{Na}_{2} \mathrm{HAsO}_{4} .7 \mathrm{H}_{2} \mathrm{O}$ (Asa) $0.9 \mathrm{mg}, \mathrm{NaAsO}_{2}$ (Asi) $0.33 \mathrm{mg}$, or $\mathrm{KSbO}$ $\mathrm{C}_{4} \mathrm{H}_{4} \mathrm{O}_{6}(\mathrm{Sb}) 12.5 \mu \mathrm{g}$. Zinc $(\mathrm{Zn})$ was tested as $\mathrm{Zn}$ $\left(\mathrm{NO}_{3}\right)_{2} .6 \mathrm{H}_{2} \mathrm{O}$.

For MIC determinations, $0 \cdot 3 \mathrm{CY}$ agar without added calcium was used for arsenicals and $\mathrm{Sb}$, NA for $\mathrm{Cd}$, and peptone agar (Oxoid) for $\mathrm{Hg}$. NA at pH 6.8 was used for the determination of the MICs of $\mathrm{Zn}{ }^{32}$ Doubling dilutions of the salts were used for MIC tests except with $\mathrm{Zn}$, for which closely graded concentrations were used. In MIC tests, isolates were graded as resistant or sensitive respectively as follows: $\mathrm{Cd} \geqslant 64$ and $\leqslant 4.0 \mathrm{mg} / \mathrm{L}$, inorganic $\mathrm{Hg} 1.25-5.0$ and $\leqslant 0.63$ $\mathrm{mg} / \mathrm{L}$, phenyl $\mathrm{Hg} 0.125-0.5$ and $\leqslant 0.063 \mathrm{mg} / \mathrm{L}$, Asa $2.0-4.0$ and $0.25-1.0 \mathrm{~g} / \mathrm{L}$, Asi $0.25-0.5$ and $\leqslant 0.06$ $\mathrm{g} / \mathrm{L}, \mathrm{Sb} 0 \cdot 2-0 \cdot 4$ and $\leqslant 0 \cdot 1 \mathrm{~g} / \mathrm{L}$. Because $\mathrm{Zn}$ MIC values varied between experiments, susceptibility was expressed as a ratio ${ }^{9}$ of the MIC value for the test strain to that for the sensitive control strain $8325 \mathrm{NR}$. Strains with moderate resistance to $\mathrm{Cd}$ (MIC 8-16 $\mathrm{mg} / \mathrm{L}$ ) were not reliably detected with disks containing 20 ,
10,5 or $2.5 \mu \mathrm{g}$ of the metal salt. Methicillin MICs were determined on NA at an incubation temperature of $30^{\circ} \mathrm{C}$, and at $30^{\circ} \mathrm{C}$ and $37^{\circ} \mathrm{C}$ to test for heterogeneity. Inocula were overnight TSB cultures diluted 1 in 100 in phosphate-buffered saline. End-points were read as an 100-fold or greater reduction in cfu at 24 or $48 \mathrm{~h}$.

\section{Loss of resistance}

Sensitive variants of methicillin-resistant strains were isolated after growth in NB and storage at room temperature for 28 days or longer. Cultures diluted to give 100-200 colonies per plate were replicated on to NA and NA with methicillin $4 \mathrm{mg} / \mathrm{L}$. Loss of $\mathrm{Cd}$ or Pi resistance was detected after growth for $24 \mathrm{~h}$ in NB at $43-44^{\circ} \mathrm{C}$ and replication on to agar containing $\mathrm{Cd} 5$ or $10 \mathrm{mg} / \mathrm{L}$ or Pi $100 \mathrm{mg} / \mathrm{L}$. Loss of $\beta$-lactamase production was detected ${ }^{31}$ by replication to starch $0.2 \% \mathrm{w} / \mathrm{v}$ agar, and the result was developed with a solution containing benzylpenicillin $600 \mathrm{mg}$ in $20 \mathrm{ml}$ of $0.1 \mathrm{M}$ phosphate buffer, $\mathrm{pH} 6.0$, with $64 \mathrm{~mm}$ iodine prepared in $120 \mathrm{~mm}$ potassium iodide.

\section{Preparation of plasmid DNA}

Plasmid DNA was isolated by a method based on that described by Stiffler et al. ${ }^{33}$ (K.G.H. Dyke, personal communication). Strains were grown in CY broth $^{31}$ to late logarithmic phase, harvested and washed with $10 \mathrm{mM}$ cold EDTA, pH 7.0, treated with 2 volumes of ethanol:acetone $(1: 1)$ for $20 \mathrm{~min}$ at $4^{\circ} \mathrm{C}$ followed by addition of 4 volumes of $10 \mathrm{~mm}$ EDTA,

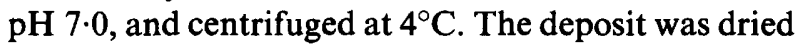
in a dessicator and resuspended in 0.05 $\mathrm{M}$ EDTA with $0.1 \mathrm{M}$ or $2.5 \mathrm{M} \mathrm{NaCl}, \mathrm{pH} 7 \cdot 0$. Harvested cells were treated with lysostaphin (Sigma) $15 \mathrm{mg} / \mathrm{L}$ in $0.05 \mathrm{M}$ EDTA, $0.1 \mathrm{M} \mathrm{NaCl}, \mathrm{pH} \mathrm{7.0,}$, at $37^{\circ} \mathrm{C}$ until the start of lysis $(c .1 \mathrm{~h})$. Lysis was completed at $4^{\circ} \mathrm{C}$ after the addition of $5 \mathrm{M} \mathrm{NaCl}(\mathrm{pH} \mathrm{7.0)} 0.17$ volumes, $0.5 \mathrm{M}$ EDTA (pH 7.0) 0.09 volumes and SDS $2 \%$ in $0.7 \mathrm{M}$ $\mathrm{NaCl}, 0.8$ volumes. The cleared lysate (supernate) was obtained by centrifugation at $44000 \mathrm{~g}$ at $4^{\circ} \mathrm{C}$ for $45 \mathrm{~min}$. After treatment with TI RNAase 5-10 units/ $\mathrm{ml}$ and pancreatic RNAase $50 \mathrm{mg} / \mathrm{L}$, for $1 \mathrm{~h}$ at $37^{\circ} \mathrm{C}$, followed by pronase $50 \mathrm{mg} / \mathrm{L}$ for $1 \mathrm{~h}$ at $37^{\circ} \mathrm{C}$, DNA was precipitated with $0 \cdot 1$ volume of $3 \mathrm{M}$ sodium acetate and 2.5 volumes of $96 \%$ ethanol at $-20^{\circ} \mathrm{C}$ and stored at $-70^{\circ} \mathrm{C}$. The precipitate was deposited by centrifugation $\left(16000 \mathrm{~g}, 4^{\circ} \mathrm{C}, 20 \mathrm{~min}\right)$, dried in a desiccator,

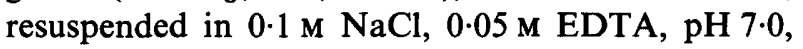
and stored at $4^{\circ} \mathrm{C}$.

\section{Transduction}

Phages $83 \mathrm{~A}, 80,80 \alpha$ and 24 were purified on the donor strain by single plaque purification and propagation by soft agar layer, or on the surface of lawn plates, by standard methods. Lysogenic donor strains insensitive to available phages were induced by exposure to UV light. Late logarithmic-phase cultures 
Table II. Resistance to metal ions in methicillin-resistant and methicillin-sensitive $S$. aureus

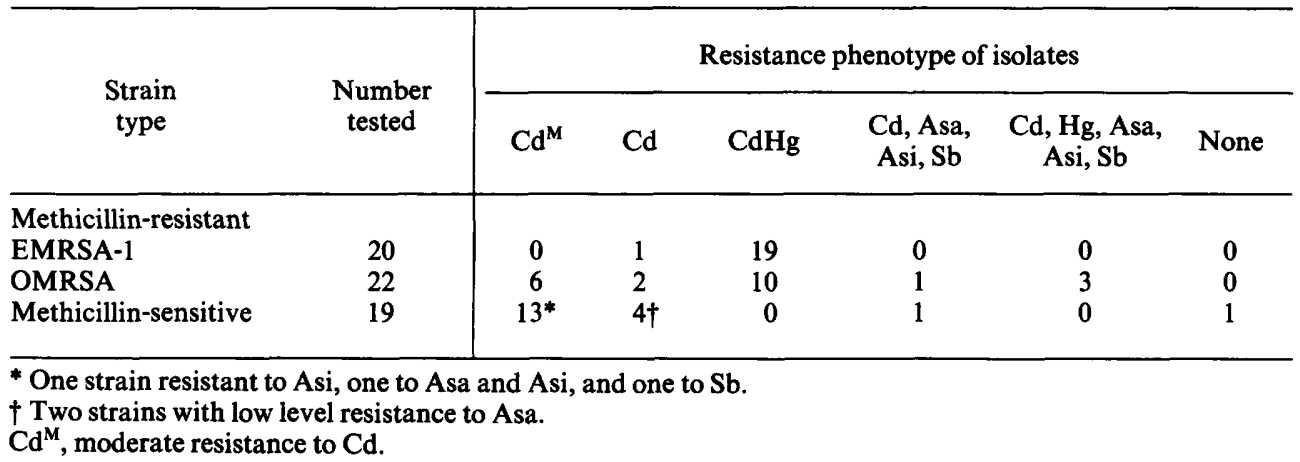

(c. $\left.3 \times 10^{8} \mathrm{cfu} / \mathrm{ml}\right)$ were washed in phosphate-buffered saline and exposed to a Hanovia monochromatic UV source for $15 \mathrm{~s}$ at a distance of $23 \mathrm{~cm}$. After the addition of $0 \cdot 1$ volume of $10 \times \mathrm{NB}$, irradiated cultures were grown with shaking for 2-3 h and left to lyse overnight. Phage lysates were harvested and filtered through a $0.45-\mu \mathrm{m}$ pore filter (Millipore). The propagating strain was tested for resistance. Transduction experiments based on methods previously described ${ }^{23}$ used input ratios of $0 \cdot 1-1 \cdot 0$. Selection for methicillin resistance was by plating on the surface of TSA plates containing methicillin 2,3 or $4 \mathrm{mg} / \mathrm{L}$. Recovery was unreliable in layer plates. Clavulanic acid (provided by Beecham Pharmaceuticals) was used at $1.5 \mathrm{mg} / \mathrm{L}$ in some experiments to inhibit background (recipient) growth. Plates were incubated at $30^{\circ} \mathrm{C}$ for $48 \mathrm{~h}$. Transductants for Cd resistance were recovered on NA with $\mathrm{CdSO}_{4}$. $8 \mathrm{H}_{2} \mathrm{O} 4$ or $10 \mathrm{mg} / \mathrm{L}$ and for tetracycline resistance on TSA containing tetracycline $20 \mathrm{mg} / \mathrm{L}$. Recovery media contained $0.1 \mathrm{mM}$ sodium citrate. Phage sterility was tested on selective media. In methicillin resistance transduction experiments, reconstruction experiments were included for recovery of the donor strain in the presence of the recipient under the same conditions as the transduction experiment.

\section{Results}

\section{Resistance to metal ions}

Results of tests for susceptibility to Cd, Hs, Asa, Asi and Sb in the methicillin-resistant and methicillinsensitive isolates by disk and MIC methods are shown in table II. Strains resistant to phenyl $\mathrm{Hg}$ were also resistant to inorganic $\mathrm{Hg}$. Zn sensitivity was tested by MIC. Amongst the MRSA strains, resistance to $\mathrm{Cd}$ and $\mathrm{Hg}$ was particularly characteristic of the EMRSA1 isolates, which is consistent with the definition of this organism as a single strain. Moderate resistance to $\mathrm{Cd}\left(\mathrm{Cd}^{\mathrm{M}}\right.$; MIC $\left.8-16 \mathrm{mg} / \mathrm{L}\right)$ occurred in six OMRSA strains and was common in the methicillin-sensitive isolates (13 out of 19). All of the Cd-resistant isolates, including those with moderate resistance, were 2-5fold more resistant to $\mathrm{Zn}$ than the sensitive control strain $8325 \mathrm{NR}$. Resistance to Asa, Asi and $\mathrm{Sb}$ in addition to $\mathrm{Cd}$ and $\mathrm{Hg}$, was observed in only three MRSA isolates (table II). In disk tests for Asa sensitivity, some strains, including EMRSA-1, showed a reduced zone size ( $>10 \mathrm{~mm}$ reduction) compared with the control, which could not be confirmed by MIC tests with closely graded concentrations. These strains were grouped as Asa-sensitive.

Eleven consecutive, epidemiologically distinct isolates of MRSA (table I) were selected for further study. On the basis of phage type, seven of the isolates represented different strains. Four of the eleven isolates were EMRSA-1 (GH13, GH25, GH28 and GH31). Two other isolates (GH19 and GH30) were very similar in phage type, antimicrobial resistances and plasmid content (results not shown), and were considered to be one strain.

\section{Resistance to methicillin}

MIC values of methicillin for the $11 \mathrm{GH}$ isolates ranged from 16 to $1024 \mathrm{mg} / \mathrm{L}$ at $30^{\circ} \mathrm{C}$ (table III). Single-colony cultures were used routinely for testing. Isolates with the highest level of resistance at $30^{\circ} \mathrm{C}$ were EMRSA-1. All isolates showed some degree of heterogeneity of resistance with MICs 2-8-fold lower at $30^{\circ} \mathrm{C}$ than at $37^{\circ} \mathrm{C}$. On repeated testing, one EMRSA-1 isolate, GH25, underwent reversible changes in MIC and in the degree of heterogeneity expressed. On initial isolation, $\mathrm{GH} 25$ was homogeneous in resistance with similar MIC values at $30^{\circ} \mathrm{C}$ and $37^{\circ} \mathrm{C}$ of $512-1024 \mathrm{mg} / \mathrm{L}$. When tested subsequently on several occasions, the initial homogeneity could not be confirmed but some heterogeneity of resistance was shown with MIC values of $512 \mathrm{mg} / \mathrm{L}$ at $30^{\circ} \mathrm{C}$ and $64 \mathrm{mg} / \mathrm{L}$ at $37^{\circ} \mathrm{C}$. However, lower MICs

Table III. MICs of methicillin at $30^{\circ} \mathrm{C}$ and $37^{\circ} \mathrm{C}$ for 11 isolates of $S$. aureus

\begin{tabular}{c|cc}
\hline \multirow{2}{*}{ Number of isolates } & \multicolumn{2}{|c}{$\mathrm{MIC}(\mathrm{mg} / \mathrm{L})$ at } \\
\cline { 2 - 3 } & $30^{\circ} \mathrm{C}$ & $37^{\circ} \mathrm{C}$ \\
\hline $4^{*}$ & $512-1024$ & $64-256$ \\
4 & $64-128$ & $8-16$ \\
3 & $16-32$ & $8-16$ \\
10442 & 128 & 16 \\
CRF612 & $512-1024$ & $16-32$ \\
\hline
\end{tabular}

* EMRSA-1. 
of $32-64 \mathrm{mg} / \mathrm{L}$ at $37^{\circ} \mathrm{C}$ and $8-16 \mathrm{mg} / \mathrm{L}$ at $37^{\circ} \mathrm{C}$ were also obtained on some occasions. When retested, a minority of colonies ( 1 in 10 tested) from one of these cultures had reverted to the higher but heterogeneous level of resistance. Furthermore, one colony from the higher level, but heterogeneous, resistant strain showed more homogeneous resistance, similar to the original isolate with MICs of $1024 \mathrm{mg} / \mathrm{L}$ at $30^{\circ} \mathrm{C}$ and $512 \mathrm{mg} / \mathrm{L}$ at $37^{\circ} \mathrm{C}$. These variants were unchanged in phage type. Passage on methicillin $(4 \mathrm{mg} / \mathrm{L})$ agar, which had been used for culture of MRSA in some cases, did not affect the levels of resistance or the degree of heterogeneity of these variants.

\section{Efficiency of plating (EOP) on methicillin agar}

Two strains, GH13 (EMRSA-1) and GH19, were responsible for outbreaks of infection. The degree of heterogeneity of methicillin resistance expressed was compared for these two strains by viable counts on methicillin agar at $30^{\circ} \mathrm{C}$ and $37^{\circ} \mathrm{C}$ (figure). The heterogeneous strains CRF 612 and 10442 were included for comparison. Strain GH13 was more resistant than strain $\mathrm{GH} 19$ at both $30^{\circ} \mathrm{C}$ and $37^{\circ} \mathrm{C}$, as shown also in MIC tests. In addition, a higher proportion of cells of strain GH13 survived (c. $\left.10^{-3}\right)$ at concentrations 2-4-fold above the MIC, compared with strain GH19 (c. $\left.10^{-5}\right)$. The results for strain GH19 were very similar to those for strain 10442 (results not shown). Strain CRF 612 showed similar levels of survival to strain GH13 $\left(c .10^{-3}\right)$ but a greater degree of heterogeneity between the two temperatures than either strain GH13 or strain GH19. Based on the classification of Hartman and Tomasz ${ }^{34}$ for the comparative survival of strains at $30^{\circ} \mathrm{C}$ and $37^{\circ} \mathrm{C}$, but using $64 \mathrm{mg} / \mathrm{L}$ instead of $50 \mathrm{mg} / \mathrm{L}$ as the test concentration, strain GH13 expressed homogeneous resistance, strains GH19 and 10442 were heterogeneous and strain CRF 612 was temperature-sensitive heterogeneous in expression of resistance.

\section{Loss and transduction of resistance to methicillin}

Loss of resistance to methicillin occurred in 10 of the 11 MRSA isolates (all except strain GH30) in 0.2$5.0 \%$ of colonies screened after storage at room temperature. When tested for other changes in sensitivity (table IV) strains GH19, GH27, GH23, GH24 and GH34 remained unchanged, although some methicillin-sensitive variants of strain GH34 lost resistance to penicillin and metal ions which was associated with loss of a large plasmid (results not shown). However, EMRSA-1 isolates and strain GH32 consistently lost resistance to $\mathrm{Cd}$ and, in most cases, resistance to $\mathrm{Hg}$ with loss of methicillin resistance (table IV). Sensitive variants also showed increased sensitivity to $\mathrm{Zn}$ of 3-4-fold compared with the parent strain. Cd MIC values for the methicillin-sensitive

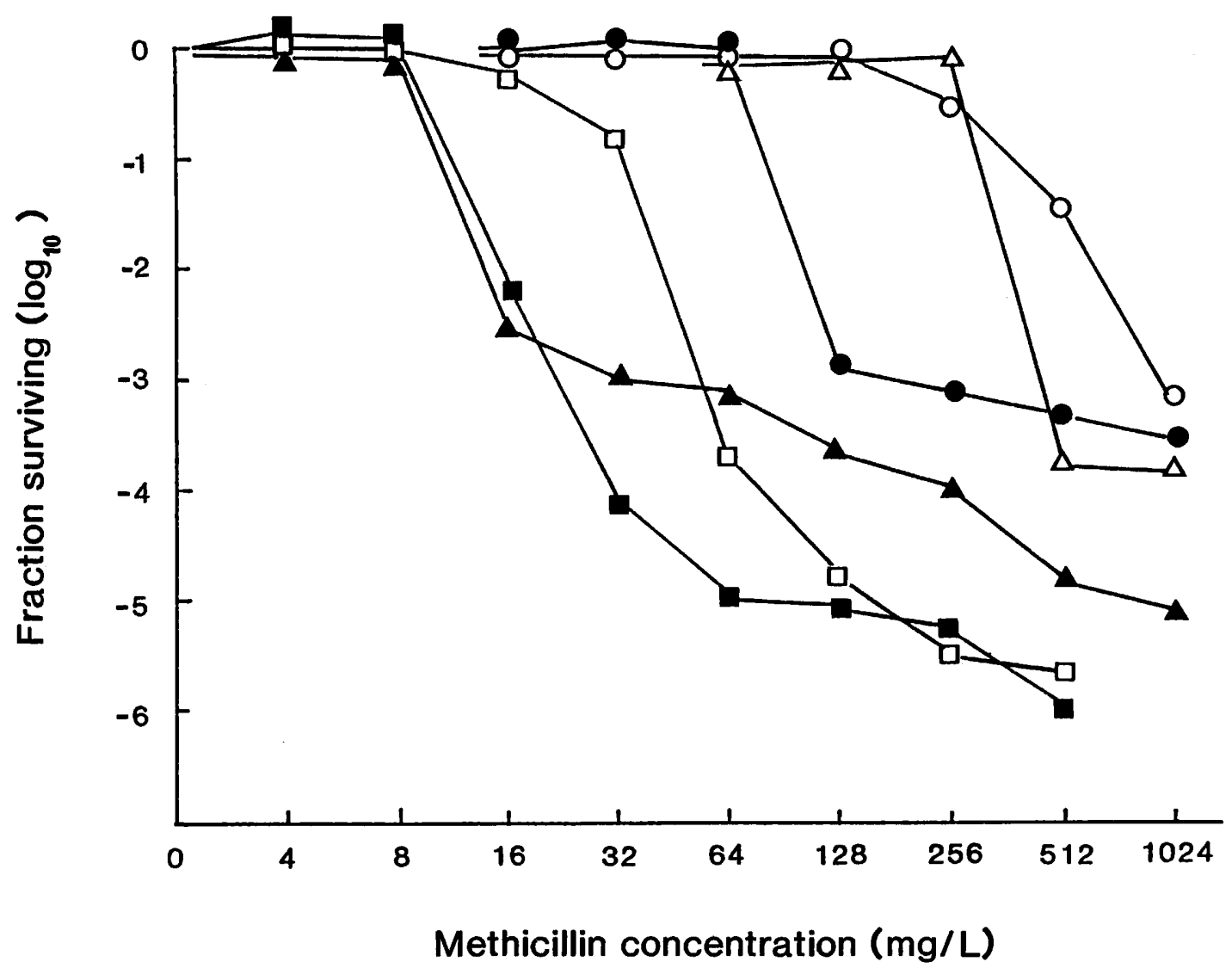

Figure. Efficiency of plating of methicillin-resistant strains $\mathrm{GH} 13$ and $\mathrm{GH} 19$ by viable counts on agar with increasing concentrations of methicillin after incubation for $48 \mathrm{~h}$ at $30^{\circ} \mathrm{C}$ or $37^{\circ} \mathrm{C}$ : strain $\mathrm{GH} 13$ at $30^{\circ} \mathrm{C} \mathrm{O}$, and $37^{\circ} \mathrm{C}$; strain $\mathrm{GH} 19$ at $30^{\circ} \mathrm{C} \square$, and $37^{\circ} \mathrm{C} \square$; sensitive control CRF612 at $30^{\circ} \mathrm{C} \triangle$, and $37^{\circ} \mathrm{C} \triangle$. 
Table IV. Co-elimination of markers with loss of methicillin or Cd resistance in MRSA

\begin{tabular}{|c|c|c|c|}
\hline \multirow{2}{*}{$\begin{array}{l}\text { Isolate } \\
\text { no. }\end{array}$} & \multicolumn{2}{|c|}{ Loss of resistance with loss of } & \multirow{2}{*}{$\begin{array}{c}\text { Associated } \\
\text { plasmid }\end{array}$} \\
\hline & Mc & $\mathrm{Cd}$ & \\
\hline $\begin{array}{l}\text { GH13* } \\
\text { GH25* } \\
\text { GH28* } \\
\text { GH31* }\end{array}$ & $\begin{array}{l}\mathrm{Cd} \mathrm{Hg} \mathrm{Tc} \\
\mathrm{Cd} \mathrm{Hg} \mathrm{Tc} \\
\mathrm{Cd} \mathrm{Hg} \mathrm{Tc} \\
\mathrm{Cd} \mathrm{Tc}\end{array}$ & $\begin{array}{l}\cdots \\
\cdots \\
\cdots \\
\cdots\end{array}$ & $\begin{array}{l}- \\
- \\
-\end{array}$ \\
\hline $\begin{array}{l}\text { GH19 } \\
\text { GH30 } \\
\text { GH27 } \\
\text { GH32 }\end{array}$ & $\begin{array}{l}0 \\
\mathrm{NA}(<0.04 \%) \\
0 \\
\mathrm{Cd} \text { Tc or Cd Hg Tc }\end{array}$ & $\begin{array}{l}\text { Pc Pi Eb Cd Hg } \\
\text { Pc Pi Eb Cd Hg } \\
\text { Pc Cd Asa Asi Sb } \\
\text { NA }(<0.02 \%)\end{array}$ & $\begin{array}{l}+ \\
+ \\
+ \\
-\end{array}$ \\
\hline $\begin{array}{l}\text { GH23 } \\
\text { GH24 } \\
\text { GH34 }\end{array}$ & $\begin{array}{l}0 \\
0 \\
0\end{array}$ & $\begin{array}{l}\mathrm{Pc} \mathrm{Cd}^{\mathrm{M}} \\
\text { Pc Cd Asa Asi Sb } \\
\text { Pc Cd Hg Asa Asi } \\
\text { Sb Sm Nm }\end{array}$ & $\begin{array}{l}+ \\
+ \\
+\end{array}$ \\
\hline
\end{tabular}

* EMRSA-1 isolates.

... Not done.

NA, not applicable.

variants of EMRSA-1 isolates were generally lower $(0.25-1.0 \mathrm{mg} / \mathrm{L})$ than control strain $8325(1-2 \mathrm{mg} / \mathrm{L})$ (table V). Their increased susceptibility was also apparent in disk tests. MICs for the sensitive variants were $2-8 \mathrm{mg} / \mathrm{L}$ compared with $1-2 \mathrm{mg} / \mathrm{L}$ for the sensitive control strain $8325 \mathrm{NR}$. In most cases, MICs for the methicillin-sensitive variants were very similar when tested at $30^{\circ} \mathrm{C}$ or $37^{\circ} \mathrm{C}$ but strains $\mathrm{GH} 23$ and GH27 showed some degree of heterogeneity with 2-4fold higher MIC values at $37^{\circ} \mathrm{C}$.

It is likely that methicillin, $\mathrm{Cd}$ and $\mathrm{Hg}$ resistances were chromosomally encoded in EMRSA-1, because loss of these markers did not result in a change of plasmid profile (results not shown) and the loss of either of two plasmids carried by these strains-a large $\mathrm{Pi}$ plasmid $(c .30 \mathrm{~kb})$ or a chloramphenicolresistance plasmid $(c .4 .3 \mathrm{~kb})$-did not affect the levels of resistance to the three markers. The EMRSA-1 isolates $\mathrm{GH} 13$ and $\mathrm{GH} 31$, and GH34, with their respective methicillin-sensitive variants were probed with a $2.6 \mathrm{~kb}$ mec-specific sequence derived from a $3.5 \mathrm{~kb}$ mec-associated region of $\mathrm{DNA}^{35}$ following digestion of preparations of DNA with restriction enzyme $B g l$ II. Strain GH13 and its sensitive variant were also tested with a mer-B probe. This confirmed

Table V. MICs to tetracycline, $\mathrm{Cd}$ and $\mathrm{Hg}$ in methicillinsensitive variant strains of EMRSA-1 and GH32

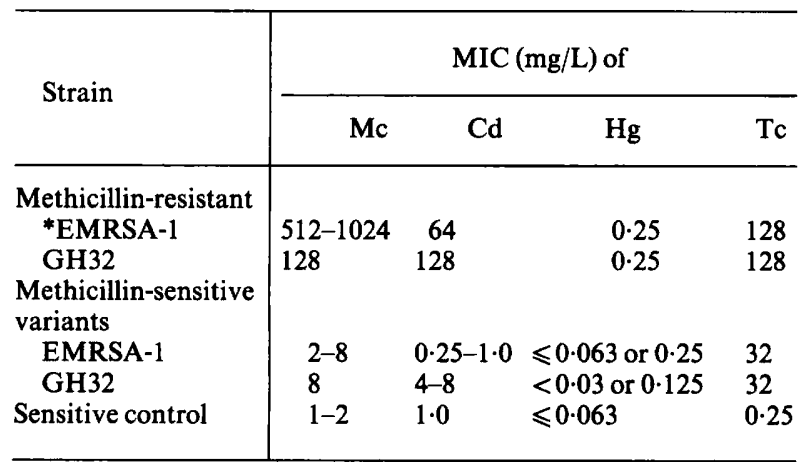

* Four isolates. that DNA associated with the mec region had been deleted in the methicillin-sensitive variant strains (B. Berger-Bächi, personal communication).

Transduction of resistance to methicillin occurred with strain GH34 as donor and the non-lysogenic, chromosomal $\beta$-lactamase-producing strain $80 \mathrm{CR} 5$ as recipient. Transduction frequencies of $\left(1.3 \times 10^{-7}\right)$ $\left(6.5 \times 10^{-8}\right) / \mathrm{pfu}$ were obtained with UV-irradiated phage 80. MIC values for the methicillin transductants were substantially higher than for the donor strain with values of $>1024 \mathrm{mg} / \mathrm{L}$ at $30^{\circ} \mathrm{C}$ and $1024 \mathrm{mg} / \mathrm{L}$ at $37^{\circ} \mathrm{C}$ for the transductants compared with $32-64 \mathrm{mg} /$ $\mathrm{L}$ at $30^{\circ} \mathrm{C}$ and $8-16 \mathrm{mg} / \mathrm{L}$ at $37^{\circ} \mathrm{C}$ for the donor strain GH34. Passaging strain GH34 on methicillin (4 mg/ L) agar, which was used for isolation and purification of transductants, did not affect the MIC. Methicillinresistant transductants were not recovered with the remaining strains tested. Strains GH19, GH30, GH23, GH24 and GH27, when used as donors, failed to transduce methicillin resistance to strain $80 \mathrm{CR} 5$ at frequencies of $\left(<1.0 \times 10^{-9}\right)-\left(<5.0 \times 10^{-10}\right) / \mathrm{pfu}$. Phage for transduction was $83 \mathrm{~A}$ with strain GH23, $80 \alpha$ with strain GH24 and was obtained by UV induction of the donor strain with strains GH19, GH30 and GH27. The effect on transduction of employing as recipient the lysogenic strain SA113, carrying the Cd-resistance, $\beta$-lactamase plasmid derived from the donor strains, was tested. No transductants were recovered at frequencies of $\left(<1.2 \times 10^{-9}\right)$ $\left(<4 \cdot 2 \times 10^{-10}\right) / \mathrm{pfu}$. Similarly with EMRSA-1 isolate GH13 as donor, no methicillin transductants were recovered with phage 24 and several different recipients. These included strain 80CR5 (transduction frequency $<2.3 \times 10^{-9} / \mathrm{pfu}$ ), a methicillin-sensitive variant of the lysogenic strain GH19 which had a $\beta$ lactamase, $\mathrm{Hg} \mathrm{Cd}$ plasmid and a tetracycline plasmid $\left(<1.3 \times 10^{-9} / \mathrm{pfu}\right)$ and a methicillin-sensitive variant of the EMRSA-1 strain GH31 which retained $\mathrm{Hg}$ resistance with loss of methicillin, $\mathrm{Cd}$ and high level tetracycline resistances $\left(<6.3 \times 10^{-10} / \mathrm{pfu}\right)$. The latter recipient strain was used to test for the possibility that the $\mathrm{Hg}$ locus, which includes two IS-like sequences, ${ }^{36}$ might contribute to the re-introduction of genes by homologous recombination. ${ }^{37}$ Phage 24, used for transduction with EMRSA-1 as donor, had previously been shown to transduce the large Pi plasmid from strain GH13 at a low frequency of $1.0 \times 10^{-9} / \mathrm{pfu}$ and chromosomal erythromycin resistance at $2.1 \times 10^{-5} /$ pfu.

\section{Loss and transduction of resistance to $C d$}

In strains which lost methicillin-resistance independently of $\mathrm{Cd}$ resistance or other markers, the loss of Cd resistance was tested after growth at $43-44^{\circ} \mathrm{C}$ (table IV). Strain GH30, which retained methicillin resistance (2765 colonies tested), was also screened. With six isolates (GH19, GH30, GH23, GH24, GH27 and GH34), loss of Cd resistance was linked to loss of $\beta$-lactamase production and loss of a large plasmid 
(c. 26-32.5 kb). In strain GH23, which had moderate resistance to cadmium, no other phenotypic change occurred. In the two similar isolates, GH19 and GH30, additional loss of resistance to $\mathrm{Hg}$ and to $\mathrm{Pi}$ and $\mathrm{Eb}$ occurred. In strains GH27 and GH24, resistance to Asa, Asi and $\mathrm{Sb}$ was co-eliminated and, in strain GH34, multiple resistance to metal ions, including $\mathrm{Hg}$, and resistances to streptomycin and neomycin were lost with the large plasmid (table IV). Erythromycin resistance became inducible in this strain. In these six isolates, loss of the $\mathrm{Cd}$ resistance, $\beta$ lactamase-producing plasmid resulted in a reduced level of methicillin resistance of about 4-fold compared with the parent. In most cases, these variants still displayed heterogeneity when tested at $30^{\circ} \mathrm{C}$ and $37^{\circ} \mathrm{C}$, suggesting that reduced methicillin resistance resulted from a plasmid-mediated character, which could be $\beta$-lactamase production. However, with loss from strains $\mathrm{GH} 19$ and $\mathrm{GH} 30$ of the plasmid which resulted in methicillin MIC values of 4-8 mg/L, heterogeneity was not clearly detected, suggesting that methicillin resistance may have been co-eliminated in these strains. Support for a plasmid location for $\mathrm{Cd}$ resistance was obtained with strains GH19, GH30, GH27, GH23, GH24 and GH34 by transduction and selection for $\mathrm{Cd}$ resistance (table VI). In each case, a large plasmid (c. 26-32.5 kb) appeared in the transductant. The markers co-transduced with strains GH19, GH30, GH23 and GH24 as donors and strain $8325-4$ or strain SA113R as recipient were the same as those co-eliminated with $\mathrm{Cd}$ resistance, although some transductants with strain GH19 as donor lacked $\mathrm{Pi}$ and $\mathrm{Eb}$ resistance (table $\mathrm{VI}$ ). When strain GH27 was employed as donor and strain 8325 as recipient, no transductants for $\mathrm{Cd}$ resistance were recovered ( $<$ $5.0 \times 10^{-10} / \mathrm{pfu}$ ), but a low frequency of transduction was obtained $\left(1.5 \times 10^{-9} / \mathrm{pfu}\right)$ when the recipient was a rifampicin resistant mutant of a $\mathrm{Cd}$-sensitive variant of strain GH27 (GH2704). However, only about half of the transductants produced $\beta$-lactamase (table VI). When strain GH34 was the donor, transduction of $\mathrm{Cd}$ resistance confirmed the presence of neomycin and streptomycin resistance characters on the plasmid, but also showed co-transfer of kanamycin resistance

Table VI. Co-transduction of resistance markers with selection for Cd resistance in MRSA

\begin{tabular}{|c|c|c|c|}
\hline Donor & Recipient & $\begin{array}{l}\text { Transduction } \\
\text { frequency } \\
\text { (per pfu) }\end{array}$ & $\begin{array}{l}\text { Phenotype of } \\
\text { transductants }\end{array}$ \\
\hline GH19 & SA113R & $1.7 \times 10^{-7}$ & $\begin{array}{l}\mathrm{Pc} \mathrm{Pi} \mathrm{Eb} \mathrm{Cd} \mathrm{Hg} \\
\text { or Pc Cd Hg }\end{array}$ \\
\hline GH30 & SAl13R & $8.1 \times 10^{-7}$ & Pc Pi Eb Cd Hg \\
\hline GH23 & $8325-4$ & $4.4 \times 10^{-7}$ & $\mathrm{PcCd}^{\mathrm{M}}$ \\
\hline GH24 & SA113R & $5.1 \times 10^{-7}$ & Pc Cd Asa Asi \\
\hline GH27 & GH2704 & $1.5 \times 10^{-9}$ & $\begin{array}{l}\text { Pc Cd Asa Asi } \\
\text { or Cd Asa Asi }\end{array}$ \\
\hline GH34 & SAl13R & c. $10^{-6}$ & $\begin{array}{l}\mathrm{Pc} \mathrm{Km} \mathrm{Nm} \mathrm{Sm} \\
\mathrm{Em} \mathrm{Cl} \\
\mathrm{Cd} \mathrm{Hg} \mathrm{Asa} \mathrm{Asi}\end{array}$ \\
\hline
\end{tabular}

and of constitutive resistance to erythromycin and clindamycin. This strain (GH34), which phenotypically has constitutive resistance to erythromycin and clindamycin and resistance to spectinomycin, appears to have two loci for erythromycin resistance; this is being studied further.

\section{Resistance to tetracycline and minocycline}

Skinner $e t a l .{ }^{25}$ described a 4-fold reduction in the level of tetracycline resistance in an epidemic MRSA strain (ANS46) from eastern Australia which had lost resistance to methicillin, $\mathrm{Cd}$ and $\mathrm{Hg}$ (ANS62); therefore, the MICs of tetracycline for methicillinsensitive variants in this study were determined. The methicillin-sensitive variants of the four EMRSA-1 isolates, $\mathrm{GH} 13, \mathrm{GH} 25, \mathrm{GH} 28$ and $\mathrm{GH} 31$, and of strain GH32, which were the strains that showed coelimination of $\mathrm{Cd}$ and usually $\mathrm{Hg}$ resistance with methicillin, showed a 4-fold reduction in resistance to tetracycline (MIC $32 \mathrm{mg} / \mathrm{L}$ ) compared with the parent strains $(128 \mathrm{mg} / \mathrm{L})$ (table $\mathrm{V})$. The low level of minocycline resistance (MIC 1-8 mg/L) which occurred in EMRSA-1 and strain GH32 was not altered in the methicillin-sensitive variants. A low level of resistance to minocycline also occurred in strains GH23, GH24 and GH27, but strains $\mathrm{GH} 19$ and GH30 were minocycline sensitive (MIC $0.25-0.5 \mathrm{mg} / \mathrm{L}$ ). Four isolates GH19, GH30, GH24 and GH27, carried a tetracycline-resistance plasmid (c. $4.3 \mathrm{~kb})$ as shown by loss and transduction of resistance (results not shown).

\section{Discussion}

The low incidence amongst strains in this study of multiple resistance to metal ions that included $\mathrm{Cd}, \mathrm{Hg}$ and Asa, is consistent with a recent report of hospital isolates in the $\mathrm{UK}^{16}$ in which only methicillin-resistant strains were $\mathrm{Hg}$ resistant, and contrasts with earlier studies in which multiple metal-ion resistances, including $\mathrm{Hg}$, were often coded on a $\beta$-lactamase plasmid. ${ }^{10,11}$ This trend is similar to that found in Danish hospitals where multiple resistance, including $\mathrm{Hg}$, fell from $48 \%$ to $13 \%$ between 1967 and 1974 and was replaced by $\mathrm{Cd}$ - and Asa-resistant strains. ${ }^{17}$

The presence of chromosomal $\mathrm{Cd}$ and $\mathrm{Hg}$ resistance which is co-eliminated with methicillin resistance in the EMRSA-1 isolates from Guy's Hospital is further evidence for the similarity of this strain in the UK with the strain epidemic in eastern Australia. Like the Australian strain, ${ }^{24}$ the methicillin-sensitive variants were slightly more resistant to methicillin (in this study $2-8 \mathrm{mg} / \mathrm{L}$ ) than fully sensitive strains. The loss of $\mathrm{Zn}$ resistance with loss of high level Cd resistance suggests that $\operatorname{cad} \mathrm{A}^{38}$ is involved. Like the Australian strains isolated since 1970, the EMRSA-1 isolates in this study and strain GH32 were minocycline resistant (MIC $2-8 \mathrm{mg} / \mathrm{L}$ ) and tetracycline resistant (MIC $32 \mathrm{mg} / \mathrm{L}$ ) and had additional high level tetracycline 
resistance (MIC $128 \mathrm{mg} / \mathrm{L}$ ) which was lost with methicillin resistance. In the eastern Australian strains, this tetracycline-resistance determinant is equivalent to a complete insert of the tetracycline resistance plasmid pT181. ${ }^{25,26}$ Although there is no direct evidence that the same plasmid is present in the chromosome of the strains in this study, it has been found that MRSA from other sources in the UK have homology with pT181 (D. Dubin, personal communication). The residual tetracycline resistance and low level of minocycline resistance in EMRSA-1 and strain GH32, do not appear to conform to either the high level $(t m n-3106)^{39}$ or low level chromosomal resistances described by Asheshov ${ }^{40}$ in S.aureus. Strain GH32, which is very similar to the EMRSA-1 isolates in the loss of chromosomal $\mathrm{Cd}, \mathrm{Hg}$ and high level tetracycline resistance with methicillin, differs from these isolates in a number of other ways, including phage type and plasmid profile, in retaining a low level of Cd resistance $(4 \mathrm{mg} / \mathrm{L})$ in methicillin-sensitive variants, and in sensitivity to trimethoprim. It is also resistant to fusidic acid and to rifampicin, which did not occur in EMRSA-1 in this study and is not common in the UK. ${ }^{19}$ Strain GH32, which was isolated from a burns patient who had recently arrived from Greece, may have originated from outside the UK.

The clonal theory proposes that MRSA isolates are derived from a single strain on the basis of similarity in characteristics of early MRSA. ${ }^{41,42}$ These included stability and poor transferability of methicillin resistance and similarity in location of certain antibiotic resistances including plasmids for resistance to tetracycline and metal ions and for $\beta$-lactamase production. The recent epidemic strains in the $\mathrm{UK}^{5,19}$ and Australia differ from these earlier isolates in several respects. If they are derived from the earlier MRSA isolates, a considerable degree of change ${ }^{4}$ has occurred, which can be explained in part by the acquisition of antimicrobial resistance markers on the chromosome by transposition or insertion of these genes from other sources. ${ }^{15}$ The concentration of certain resistance characters in the region of methicillin resistance in MRSA, including resistance to $\mathrm{Cd}, \mathrm{Hg}$ and tetracycline, suggests a role for this region in the build up of resistance on the chromosome. It has been suggested ${ }^{37}$ that the insertion-sequence-like element (IS431) in the mec locus could provide a recombination site for resistances such as tetracycline and $\mathrm{Hg}$ which are also flanked by similar insertion sequences. ${ }^{25}$ In further support of the clonal theory for the origin of methicillin-resistant strains, it has been suggested ${ }^{43}$ that this mec-associated DNA, which may provide integration sites, was acquired early in the evolution of the strain, and that modern MRSA isolates are derived from this organism.

The plasmid phenotypes of strains GH19 and $\mathrm{GH} 30$, for resistance to $\mathrm{Pi}, \mathrm{Eb}, \mathrm{Cd}$ and $\mathrm{Hg}$ and $\beta$ lactamase production has been described in several other countries, including epidemic strains in SE Asia ${ }^{6}$ and in Dublin hospitals. ${ }^{7}$ Strain GH19, which was also responsible for an outbreak of infection, has a tetracycline plasmid $($ c. $4.3 \mathrm{~kb})$ and lacks chromosomal resistance to tetracycline and minocycline, making it more like the earlier classic isolates of MRSA. ${ }^{41,42}$

The difficulty in transducing methicillin resistance ( $m e c$ ) recognised in other studies has been confirmed in this study. Some of the reasons for failure to transduce in this study could be in the use of phages which, although shown to transduce other markers, lack characteristics required for transduction of mec. Cohen and Sweeney ${ }^{44}$ found that UV-induced lysogenic phage, which was used with four strains in this study, could not transduce methicillin if obtained directly from the donor strain (C5). Several reports have noted that phage 80 , which was the phage involved in transduction of methicillin in this study, is more effective than transducing phages 53 and $29^{44,45}$ in transducing methicillin resistance. The enhanced effect of UV light on methicillin transduction suggests that homology is involved although mec does not have an allelic site in sensitive strains. ${ }^{35,46}$ If the large $30-40-\mathrm{kb}$ mec-associated deletion found in an Australian epidemic strain ${ }^{24,25,36,47}$ has occurred in the MRSA in this study, regions of homology required for transduction may have been removed or the mec-containing fragment may be at the size limit for the transducing phage. In methicillin transduction with strain GH34 as donor, the similarity in phage type of the donor strain and strain PS80 from which the recipient strain $80 \mathrm{CR} 5$ is derived, may provide the homology necessary for transduction with this pair of strains. It was also noted that strain $80 \mathrm{CR} 5$ is nonlysogenic and plasmid free and has chromosomal $\beta$ lactamase, which are the conditions associated with transduction of methicillin-resistance by Stewart and Rosenblum, ${ }^{28}$ also with phage 80 .

We are grateful to Dr R. Springbett and C. Aubrey for provision of the Guy's Hospital clinical isolates of S. aureus and to Lesley Sarton for typing the manuscript.

\section{References}

1. Jevons MP. "Celbenin"-resistant staphylococci. Br Med J 1961 ; 1: 124-125.

2. Parker MT, Hewitt JH. Methicillin resistance in Staphylococcus aureus. Lancet 1970; 1: 800-804.

3. Sabath LD. Chemical and physical factors influencing methicillin resistance of Staphylococcus aureus and Staphylococcu. epidermidis. J Antimicrob Chemother 1977; 3 Suppl C: 4751 .

4. Townsend DE, Ashdown N, Bolton $\mathrm{S}$ et al. The international spread of methicillin-resistant Staphylococcus aureus. J Hosp Infect 1987; 9: 60-71.

5. Cookson BD, Phillips I. Epidemic methicillin-resistant Staphylococcus aureus. J Antimicrob Chemother 1988;21 Suppl C 57-65.

6. Grubb WB, Townsend DE, Ashdown N, Taheri S. A genetic 
comparison of methicillin-resistant Staphylococcus aureus isolated from different countries. In : Ishigami J (ed) Recent advances in chemotherapy. Tokyo, University of Tokyo Press. 1985: 401-402.

7. Coleman DC, Pomeroy H, Estridge JK et al. Susceptibility to antimicrobial agents and analysis of plasmids in gentamicin- and methicillin-resistant Staphylococcus aureus from Dublin hospitals. J Med Microbiol 1985; 20 : 157-167.

8. Townsend DE, Ashdown N, Momoh M, Grubb WB. Distribution of plasmid-borne resistance to nucleic acid binding compounds in methicillin-resistant Staphylococcus aureus. $J$ Antimicrob Chemother $1985 ; 15$ : 417-434.

9. Novick RP, Roth C. Plasmid-linked resistance to inorganic salts in Staphylococcus aureus. J Bacteriol 1968; 95: 13351342.

10. Peyru G, Wexler LF, Novick RP. Naturally occurring penicillinase plasmids in Staphylococcus aureus. J Bacteriol 1969; 98: 215-221.

11. Dyke KGH, Parker MT, Richmond MH. Penicillinase production and metal-ion resistance in Staphylococcus aureus cultures isolated from hospital patients. J Med Microbiol $1970 ; 3$ : 125-136.

12. Gillespie MT, May JW, Skurray RA. Antibiotic resistance in Staphylococcus aureus isolated at an Australian hospital between 1946 and 1981. J Med Microbiol 1985; 19: 137147.

13. Moore B. A new screen test and selective medium for the rapid detection of epidemic strains of Staph. aureus. Lancet 1960; 2: $453-458$.

14. Townsend DE, Ashdown N, Grubb WB. Evolution of Australian isolates of methicillin-resistant Staphylococcus aureus: a problem of plasmid incompatibility? J Med Microbiol $1985 ; 20: 49-61$.

15. Lyon BR, Skurray RA. Antimicrobial resistance of Staphylococcus aureus: Genetic basis. Microbiol Rev 1987; 51 : 88-134.

16. Millar MR, Griffin N, Keyworth N. Pattern of antibiotic and heavy-metal ion resistance in recent hospital isolates of Staphylococcus aureus. Epidemiol Infect 1987; 99: 343-347.

17. Rosdahl VT, Rosendal K. Resistance to cadmium, arsenate and mercury among Danish strains of Staphylococcus aureus isolated from cases of bacteraemia, 1957-1974. J Med Microbiol 1980; 13: 383-391.

18. Townsend DE, Grubb WB, Ashdown N. Genetics of drug resistance in methicillin-resistant Staphylococcus aureus from Australian hospitals. $J$ Hosp Infect 1983 ; 4: 331-337.

19. Marples RR, Richardson JF, de Saxe MJ. Bacteriological characters of strains of Staphylococcus aureus submitted to a reference laboratory related to methicillin resistance. $J$ Hyg (Camb) 1986; 96: 217-223.

20. Gillespie MT, Skurray RA. Plasmids in multiresistant Staphylococcus aureus. Microbiol Sci 1986; 3: 53-58.

21. Marples RR, Cooke EM. Current problems with methicillinresistant Staphylococcus aureus. J Hosp Infect 1988; 11 : 381-392.

22. Grubb WB, Annear DI. Spontaneous loss of methicillin resistance in Staphylococcus aureus at room-temperature. Lancet $1972 ; 2: 1257$.

23. Blanchard TJ, Poston SM, Reynolds PJ. Recipient characteristics in the transduction of methicillin resistance in Staphylococcus epidermidis. Antimicrob Agents Chemother 1986; 29 : 539-541.

24. Matthews PR, Reed KC, Stewart PR. The cloning of chromosomal DNA associated with methicillin and other resistances in Staphylococcus aureus. J Gen Microbiol 1987; 133: 1919-1929.

25. Skinner S, Inglis B, Matthews PR, Stewart PR. Mercury and tetracycline resistance genes and flanking repeats associated with methicillin resistance on the chromosome of Staphylococcus aureus. Mol Microbiol 1988; 2: 289-292.

26. Gillespie MT, May JW, Skurray RA. Detection of an integrated tetracycline resistance plasmid in the chromosome of methicillin-resistant Staphylococcus aureus. J Gen Microbiol $1986 ; 132$ : 1723-1728.

27. Cohen S, Sweeney HM. Effect of the prophage and penicillinase plasmid of the recipient strain upon the transduction and the stability of methicillin resistance in Staphylococcus aureus. J Bacteriol 1973; 116: 803-811.

28. Stewart GC, Rosenblum ED. Transduction of methicillin resistance in Staphylococcus aureus: recipient effectiveness and beta-lactamase production. Antimicrob Agents Chemother $1980 ; 18: 424-432$.

29. Engel HWB, Soedirman N, Rost JA, van Leeuwen WJ, van Embden JDA. Transferability of macrolide, lincomycin, and streptogramin resistances between group A, B, and D streptococci, Streptococcus pneumoniae and Staphylococcus aureus. J Bacteriol 1980; 142: 407-413.

30. Iordanescu S, Surdeanu M. Two restriction and modification systems in Staphylococcus aureus NCTC 8325. J Gen Microbiol 1976; 96: 277-281.

31. Novick RP. Analysis by transduction of mutations affecting penicillinase formation in Staphylococcus aureus. J Gen Microbiol 1963; 33: 121-136.

32. Witte W, Green L, Misra TK, Silver S. Resistance to mercury and to cadmium in chromosomally resistant Staphylococcus aureus. Antimicrob Agents Chemother 1986; 29: 663-669.

33. Stiffier PW, Sweeney HM, Cohen S. Co-transduction of plasmids mediating resistance to tetracycline and chloramphenicol in Staphylococcus aureus. J Bacteriol 1974; 120: 934-944.

34. Hartman BJ, Tomasz A. Expression of methicillin resistance in heterogeneous strains of Staphylococcus aureus. Antimicrob Agents Chemother 1986; 29 : 85-92.

35. Beck WD, Berger-Bächi B, Kayser FH. Additional DNA in methicillin-resistant Staphylococcus aureus and molecular cloning of mec-specific DNA. $J$ Bacteriol 1986; 165: 373378.

36. Gillespie MT, Lyon BR, Loo LSL, Matthews PR, Stewart PR, Skurray RA. Homologous direct repeat sequences associated with mercury, methicillin, tetracycline and trimethoprim resistance determinants in Staphylococcus aureus. FEMS Microbiol Lett 1987; 43: 165-171.

37. Berger-Bächi B. Genetics of methicillin resistance in Staphylococcus aureus. J Antimicrob Chemother 1989 ; 23 : 671-673.

38. Smith K, Novick RP. Genetic studies on plasmid-linked cadmium resistance in Staphylococcus aureus. J Bacteriol 1972; 112: 761-772.

39. Pattee PA. Genetic linkage of chromosomal tetracycline resistance and pigmentation to a purine auxotrophic marker and isoleucine-valine-leucine structural genes in Staphylococcus aureus. J Bacteriol 1976; 127: 1167-1172.

40. Asheshov EH. The genetics of tetracycline resistance in Staphylococcus aureus. J Gen Microbiol 1975; 88: 132-140.

41. Lacey RW. Genetic control in methicillin-resistant strains of Staphylococcus aureus. J Med Microbiol 1972; 5: 497-508.

42. Lacey RW, Grinsted J. Genetic analysis of methicillin-resistant strains of Staphylococcus aureus: evidence for their evolution from a single clone. J Med Microbiol 1973; 6: 511-526.

43. Tillotson LE, Jenssen WD, Moon-McDermott L, Dubin DT. Characterization of a novel insertion of the macrolideslincosamides-streptogramin B resistance transposon Tn554 in methicillin-resistant Staphylococcus aureus and Staphylococcus epidermidis. Antimicrob Agents Chemother 1989; 33: 541-550.

44. Cohen S, Sweeney HM. Transduction of methicillin resistance in Staphylococcus aureus dependent on an unusual specificity of the recipient strain. $J$ Bacteriol $1970 ; 104$ : 11581167.

45. Kayser FH, Wüst J, Corrodi P. Transduction and elimination of resistance determinants in methicillin-resistant Staphylococcus aureus. Antimicrob Agents Chemother 1972; 2: 217 223.

46. Stewart GC, Rosenblum ED. Genetic behavior of the methicillin resistance determinant in Staphylococcus aureus. $J$ Bacteriol 1980; 144: 1200-1202.

47. Inglis $B$, Matthews $P R$, Stewart $P R$. The expression in Staphylococcus aureus of cloned DNA encoding methicillin resistance. J Gen Microbiol 1988; 134: 1465-1469. 
